IFAS Extension

\title{
Datos sobre la niacina ${ }^{1}$
}

\section{R. Elaine Turner y Wendy J. Dahl'}

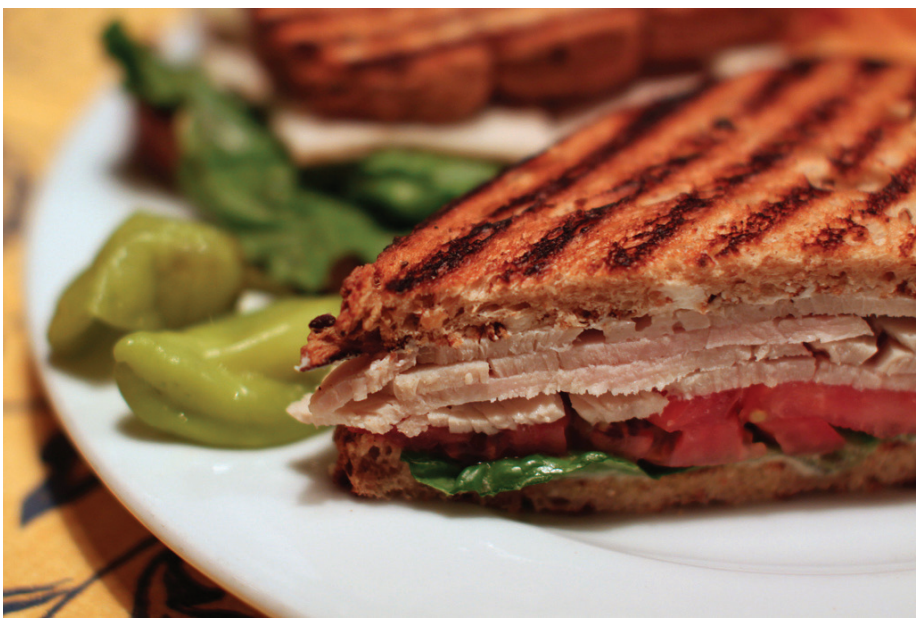

Figura 1. Sándwich a la parrilla con pavo y pan integral Credits: Mr. T in DC (CC BY-ND 2.0) http://flic.kr/p/6R5656

\section{¿Por qué necesitamos la niacina?}

La niacina es una de las vitaminas del grupo B (vitamina $B_{3}$ ). Nuestro cuerpo necesita la niacina para usar los carbohidratos, las grasas y las proteínas. La niacina también se necesita para reparar el ADN y para el uso normal del calcio en el cuerpo.

\section{¿Qué pasa si no consumimos suficiente niacina?}

La pelagra es una enfermedad que se presenta cuando la persona no obtiene suficiente niacina. Esta enfermedad era común en los años 1800 cuando muchos estadounidenses pobres se alimentaban mayormente de maíz, melazas y cerdo curado con sal, los cuales son fuentes pobres de niacina. Hoy en día, la mayoría de las personas obtienen suficiente niacina en sus dietas ya que esta vitamina se encuentra en muchos de los alimentos que consumimos y así la pelagra es cosa del pasado.

La pelagra podría ser llamada la enfermedad de la “D." Esta enfermedad conlleva a la diarrea, la demencia (desorden de la memoria), la dermatitis (erupciones en la piel) y el deceso (muerte).

\section{¿Cuánta niacina necesitamos?}

La tabla 1 muestra la cantidad diaria de niacina recomendada.

Tabla 1. Ingesta diaria de niacina recomendada en diferentes etapas de vida

\begin{tabular}{|c|c|}
\hline Etapa de vida & Niacina $(\mathbf{m g} /$ día) \\
\hline Hombres, edades 19+ & 16 \\
\hline Mujeres, edades 19+ & 14 \\
\hline Embarazo & 18 \\
\hline Lactancia & 17 \\
\hline \multicolumn{2}{|c|}{$\mathrm{mg}=$ miligramos } \\
\hline
\end{tabular}

\section{¿Cómo podemos obtener suficiente niacina?}

La niacina se encuentra en granos enteros tales como el arroz integral y el pan de trigo entero. Si usted no elige alimentos de trigo integral, asegúrese de elegir alimentos enriquecidos. La niacina es una de las cuatro vitaminas que

1. The English version of this document is FCS8669/FY212 Facts about Niacin. Este documento, FCS8669s, es uno de una serie de publicaciones del Departamento de Ciencias de la Familia, la Juventud y la Comunidad, Servicio de Extensión Cooperativa de la Florida, Instituto de Alimentos y Ciencias Agrícolas, Universidad de la Florida (UF/IFAS). Fecha de primera publicación noviembre de 2012. Visite EDIS en http://edis.ifas.ufl.edu.

2. R. Elaine Turner, PhD, RD, profesora y decano asociada, College of Agricultural and Life Sciences; Wendy J. Dahl, PhD, RD, profesora asistente, Food Science and Human Nutrition Department, Universidad de la Florida, Gainesville, FL 32611. 
se añaden a los productos de trigo enriquecidos tales como el cereal y la pasta. Busque la palabra "niacina" en la lista de ingredientes para ver si ha sido añadida.

Otras fuentes buenas de niacina son el maní, los champiñones y los mariscos. La tabla 2 muestra algunos alimentos y la cantidad de niacina que contienen.

INGREDIENTES: Harina enriquecida (niacina, hierro, mono-nitrato de tiamina, riboflavina, ácido fólico), agua, fibra de trigo, polvo de hornear)...

Tabla 2. Ejemplos de alimentos y su contenido de niacina por porción

\begin{tabular}{|c|c|}
\hline Alimento & Niacina (mg por porción) \\
\hline Salmón, cocido, 3 oz & 7 \\
\hline Pavo, carne blanca, cocido, 3 oz & 6 \\
\hline Cereal listo para comer, 1 taza & 5 \\
\hline $\begin{array}{l}\text { Carne, molida sin grasa, cocida, } \\
3 \mathrm{oz}\end{array}$ & 5 \\
\hline Mantequilla de maní, 2 Cda & 4 \\
\hline Champiñones, cocido, $1 / 2$ taza & 3 \\
\hline $\begin{array}{l}\text { Espagueti, enriquecido, cocido, } \\
1 \text { taza }\end{array}$ & 2 \\
\hline \multicolumn{2}{|c|}{$\begin{array}{c}\mathrm{mg}=\text { miligramos } \\
\mathrm{Oz}=\text { onzas } \\
\mathrm{Cda}=\text { cucharada }\end{array}$} \\
\hline
\end{tabular}

\section{¿Sabia usted que...?}

El triptófano es uno de los aminoácidos que forman la proteína y este puede ser convertido en niacina por el cuerpo. El triptófano se encuentra en todos los tipos de carnes y en la leche, por lo tanto estos alimentos se pueden considerar una buena fuente de niacina.

\section{¿Cómo deben ser preparados los alimentos para retener la niacina?}

La niacina se puede perder cuando los alimentos se cocinan en agua debido a que la niacina es una vitamina hidrosoluble. Sin embargo, la mayoría de las fuentes buenas de niacina no se cocinan en agua. El cocinar los alimentos no afecta el contenido del triptófano.

\section{¿Qué pasa con los suplementos?}

La mayoría de la personas obtienen suficiente niacina en sus dietas, por lo tanto los suplementos usualmente no se necesitan. La mayoría de los suplementos multivitamínicos contienen niacina. No hay necesidad de tomar suplementos con más del 100\% del valor diario de niacina.

\section{¿Qué cantidad es demasida?}

El consumo máximo de niacina que es sugerido para suplementos es $35 \mathrm{mg}$ diarios para personas mayores de 19 años, y $30 \mathrm{mg}$ para personas menores de 19 años (1).

Las dosis muy altas de niacina (1,300 a 3,000 mg diarios) se usan a veces para tratar los niveles altos de colesterol en la sangre. Sin embargo, pueden causar efectos secundarios tales como enrojecimiento del la piel, picazón, nausea, incremento de glucosa en la sangre, úlceras en el estómago y hasta daños en el hígado. Las nuevas formas de suplementos de dosis altas de niacina son preparaciones de liberación prolongada para reducir al mínimo estos efectos secundarios (3). ¡No consuma grandes cantidades de niacina a menos que haya sido prescrito por su médico! Avise a su médico si tiene algún efecto secundario por tomar suplementos de niacina.

\section{¿Dónde puedo obtener más información?}

El agente de Ciencias de la Familia y del Consumidor (FCS) en la oficina de extensión de su condado puede tener más información escrita y clases de nutrición para que usted asista. También, un dietista registrado $(\mathrm{RD})$ puede proveerle información confiable.

Más información nutricional confiable se puede encontrar en los siguientes sitios del Internet:

http://fycs.ifas.ufl.edu

http://www.eatright.org

http://www.nutrition.gov

\section{Referencias}

1. Food and Nutrition Board. Dietary Reference Intakes for Thiamin, Riboflavin, Niacin, Vitamin B6, Folate, Vitamin B12, Pantothenic Acid, Biotin, and Choline. Washington, DC: National Academy Press, 1998, pp. 123-49.

2. U.S. Department of Agriculture, Agricultural Research Service. 2009. USDA National Nutrient Database for Standard Reference, Release 22. Nutrient Data Laboratory Home Page, http://www.ars.usda.gov/ba/bhnrc/ndl.

3. Gropper, S. \& Smith, J. (2008). Advanced nutrition and human metabolism ( $5^{\text {th }}$ ed). Mason, $\mathrm{OH}$ : Cengage Learning. 